\title{
ELECTRE TRI METHOD USED TO STORAGE LOCATION ASSIGNMENT INTO CATEGORIES
}

\author{
Marcele Elisa Fontana* and Cristiano Alexandre Virgínio Cavalcante
}

Received November 11, 2011 / Accepted January 30, 2013

\begin{abstract}
Day after day, the importance of a company having an efficient storage location assignment system increases. Moreover, since products have different warehouse costs and customers' requirements are also different, it is important to sort products in order to adopt strategies for inventory management that are appropriate for each product. However, adopting a policy for each product is not applicable in the real world. Therefore, companies usually categorize products into classes and thereafter adopt specific inventory management policies. Given this situation, this paper puts forward the arguments for adopting a multi-criteria method, Electre TRI, to sort products that both considers criteria relating to the characteristics of a product as to its physical location in the warehouse and the criteria that are important for inventory strategies, such as, for example, the profitability of each unit held in storage.
\end{abstract}

Keywords: sorting, storage location assignment, stock management policies, electre TRI method.

\section{INTRODUCTION}

Storage is one of the most traditional areas of logistics. According to Goebel (1996), for a warehouse to function properly, a system requires to be developed that transfers the cargo rapidly from the origin of the product to its destination, and by so doing immobilizes a company's resources for the shortest possible time. For Daniels et al. (1998), changes in demand and a consequent redistribution of warehouse spaces, often, require the movement of stocks that may well cause serious disruption in warehouse operations, especially when the warehouse is often used.

Moreover, storage decisions can influence almost all the key performance indicators of a warehouse, such as: the time taken to pick orders; the cost of storage space used, labor and order picking, etc (Li et al., 2008). The efficiency of handling operations and storage depends on the degree to which the layout has been well-planned. When pursuing such internal efficiency, it is important to check that the current layout of the warehouse is not operating as a bottleneck and to verify if the available resources are sufficient for a rapid and efficient logistics operation (Freitas

*Corresponding author

Federal University of Pernambuco - UFPE, Brazil. E-mails: marcelelisa@gmail.com; cristiano@ufpe.br 
et al., 2006). However, changes in warehouse layout require high investment. Thus, after the layout has been designed, other strategies must be devised to ensure warehousing activities are efficient as possible (Chen et al., 2005). Examples are: assigning items to the correct storage location and, consequently, having an efficient order picking system.

There are three categories in a storage location assignment system: dedicated storage, random storage, and class-based storage. In dedicated storage there is a rise in the cost of using space when such space is used poorly, while under random storage, much effort is placed on the order picking system. Class-based storage combines features of the prior two systems and can be a good alternative for making a warehouse more efficient in terms of the space used and the order picking operation, as well as for minimizing warehouse costs. However, most categorization methods used to generate a class-based storage system, usually, consider just the physical characteristics of the products, i.e., they exclude important features such as the company's profitability.

In addition, the number of stock-keeping units (SKUs) in the largest firms can easily reach tens of thousands. Clearly, it is not economically feasible to design a stock management policy for each individual SKU (Chen et al., 2008). This is why companies commonly use a means to categorize products, such as the ABC curve, so as to adopt specific policies for each class (Chu et al., 2008). Therefore, this paper proposes using a multi-criteria outranking method, Electre TRI, to construct a storage location assignment system in a warehouse. In other words, by using Electre TRI, it is possible to assign each item or product to class-based storage, according to the decision maker's preferences, and this categorization can aid making decisions about the inventory.

This paper is structured as follows. Section 2 presents some important general concepts. Section 3 gives a brief introduction to multicriteria decision aid, more specifically the Electre TRI method. The steps of the proposed model and an illustrative example are presented in Section 4. Next, some discussions are made and attention is drawn to some limitations. Finally, some conclusions are drawn in Section 6.

\section{ORDER PICKING SYSTEM IN A WAREHOUSE}

Since warehousing activities are frequent and numerous, even small improvements can achieve significant savings (Chen et al., 2005). Order picking has been considered as the most critical operation in warehousing. Jane \& Laih (2005) define order picking as the process by which the appropriate amounts of products are taken from a specific location in stock to fulfil clients' orders.

The most common objective of order picking systems is to maximize the level of services subject to resource constraints, such as: labor, machinery and capital (Goetschalckx \& Ashayeri, 1989 apud Koster et al., 2007). The efficiency of an order picking process greatly depends on the storage policy used, i.e. where products are located within the warehouse (Le-Duc \& Koster, 2005).

Selecting a method for order picking is a strategic decision, since it has a broad impact on many other decisions when designing and operating a warehouse (Gu et al. (2007). Four methods 
can be used to reduce the distances traveled to pick items for an order and, consequently, to reduce the time required for this, such as: 1) Determining a route for picking; 2) Zoning the warehouse; 3) Allocating the batching of orders; 4) Assigning items to the correct location warehouse (Muppani \& Adil, 2008a).

Petersen \& Aase (2004) report that selecting routes comes up with policies for minimizing the distance traveled by the picker, and hence the time needed, by using simple heuristics or optimal procedures.

Koster et al. (2007) argued that the picking area can be divided into zones as an alternative to single order picking. Each picker is assigned to part of the order that is in their area. Possible advantages of zoning include the fact that each order in the picker must traverse a smaller area, traffic congestion is reduced, and there is the possibility of these pickers familiarizing themselves with the locations of items in their zone. The main disadvantage of zoning is that the orders are separated and must be consolidated again before shipment to the customer.

An order contains all the products and quantities requested by a client or a production/ assembly job - in the case of a distribution center or production warehouse, respectively. When an order contains multiple SKUs, they must be collected and sorted before they are transported to the shipping area or the production line (Van Den Berg \& Zijm, 1999).

Thus, a batch is a set of orders that are grouped to be selected together in one trip (picking). For this approach, orders must be consolidated before picking operations begin (Chen \& Wu, 2005). The main decision involved in order batching is when a particular set of customer orders should be combined so that the total length of all trip needed to pick all the items is minimized (Henn et al., 2010).

\subsection{Storage location assignment system}

According to Gu et al. (2007) different storage strategies can be used. Selecting which storage strategy to use is considered a design problem. However, how to implement each storage strategy is an operational issue. Three categories of storage location assignment system are presented by Hausman et al. (1976 apud Li et al., 2008): fixed or dedicated storage, random or variable storage, and class-based storage.

A dedicated storage policy prescribes a particular location for the storage of each product (Rouwenhorst et al., 2000), such that no other item can be stored there, even if the space is empty. Under a dedicated storage policy each storage area may only be used for a specific item. The materials are placed in existing open spaces. A randomized storage policy allows items to be stored anywhere in the storage area. Randomized and dedicated storage are extreme cases of class-based storage policy: randomized storage considers a single class and dedicated storage considers one class for each item (Muppani \& Adil, 2008a).

To allocate classes in a warehouse Hesket, in 1963, proposed the cube-per-order index (COI). This captures the popularity of the item and its storage space condition, which is expressed as 
the ratio of storage space required (cube) per SKU and the order frequency of the SKU (Brynzér $\&$ Johansson, 1996). The rule ranks the items in ascending order of the index, and then it assigns them in that order to the locations nearest the I/O (Input/Output) point, in order to reduce the cost of order picking (Jane \& Laih, 2005).

According to Goetschalckx \& Ratliff (1990 apud Muppani \& Adil, 2008a), allocating items based on COI values gives optimal allocation in terms of order picking/storing time under a dedicated storage policy for a single command transaction. Hackman \& Rosenblatt (1990 apud Van Den Berg et al., 1998) were the first to present a model which simultaneously considers both assignment (which products) and allocation (in what amounts). They describe a heuristic that attempts to minimize the total costs for picking and replenishing.

Brynzér \& Johansson (1996) describe a strategy to pre-structure components (items) by structuring the products processed in the problems of the Stock Location Assignment Problem - SLAP. For Leung \& Wang (2000 apud Li et al., 2008) the problem of storage location assignment is a multi-objective optimization (MOP), as it tries to location assignment using goals that may be conflicting. Hsieh \& Tsai (2001) presented a 'Bill Of Material' (BOM) oriented method for assigning stock location in a class-based way for an AS/RS system.

A model of order picking with a general storage location assignment in a rectangular warehouse system is presented by Chew \& Tang (1999). This paper presents the exact probability density function that characterizes the tour of an order picker. Petersen \& Aase (2004) analyze the effect of three decisions of the storage process (picking, routing and allocation of items) on order picker travel, which is a major cost in meeting a customer order. The authors use a simulation model and sensitivity analysis.

Daniels et al. (1998) formulated a heuristic model for simultaneously determining decisions about storage location assignment and order picking sequencing, and compared this with previous order picking models. That same year, a genetic algorithm was proposed by Li et al. (2008), with Pareto optimization and a technical niche, for storage location assignment so as to optimize the storage space required and the efficiency of order picking in an automated warehouse.

Muppani \& Adil in 2008 (a) used simulation annealing and (b) a model for integer programming (Branch and Bound) to randomly distribute products within a class-based storage system. They used the COI index to determine these class-based categories. They compared their results with the dynamic programming algorithm proposed by Van Der Berg (1996) while Meghelli-Gaouar $\&$ Sari (2010) present the results of a comparative study carried out by simulation which includes class-based storage, purely random storage and a heuristic method for storage.

Fontana \& Cavalcante (2010) based on the COI index methodology proposed two new indices, with the general objective of examining the impact of using the number of customers in the storage location assignment in terms of space usage and order picking. The first index is the cube-per-consumer (CIC) which is the ratio of space required times the number of customers, and the second is the cube-per-order and consumer (COIC) which is the ratio of space required by order frequency times the number of customers. 
The use of the index COI, for example, is very common in the literature for class formation and location assignment in a warehouse. However, defining a class of products for the purpose of storage location involves various aspects, which cannot be described based solely on the COI index. Basically, this kind of index aggregates the product characteristics into just one value, which, subsequently, is used in a combinatorial nonlinear programming algorithm to determine the class formation and location assignment in the warehouse. Despite the optimization of one objective being the approach that is most used for class formation, this could be very restrictive especially where conflicting objectives should be taken into account.

In fact, class formation basically consists of defining the best class (among an already defined set of classes) that best suits the characteristics of each product, based on some aspects and on the decision maker's preferences. This problem is known as a sorting problem under the multicriteria decision aid approach (MCDA) (Roy, 1996; Bouyssou \& Marchant, 2005). There are various multi-criteria sorting methods. Electre TRI is one of the most used multicriteria methods designed to assist the decision maker in sorting some alternatives into some predefined classes. Although it could be interesting to address the problem of class formation for the purpose of storage location by enriching it by using an MCDA approach, as far as we know, nothing has been published in the literature that proposes classes of product based on a multi-criteria decision method for the same purpose as the one that is put forward in this article.

Therefore, the use of the Electre TRI method enables the characteristics which influence class formation and location, such as its demand and the space required for storage to be considered simultaneously with essential features for inventory management, such as the profitability of products. Thus, the Electre TRI method enables the advantages of an index, such as COI, and the $\mathrm{ABC}$ curve to be combined. Thus, a class formation and location in the warehouse can be obtained which seeks, at the same time: a lower space requirement, a shorter travel distance in order-picking and enables stock management that is specific to each class of products.

\section{MULTICRITERIA DECISION AID (MCDA)}

The great advantage of the multicriteria approach lies in the fact that, at one time, several tradeoffs between the alternatives are found, thus providing the set of optimal solutions with a different level of compromise between the conflicting goals (Nicolini \& Zovatto, 2009). Given the importance of multi-criteria methods in dealing with human reality, several approaches have been proposed. All of them replace the search for the optimal solution for those of greatest commitment. They are used to support people and organizations in the decision-making process (Alencar \& Almeida, 2008). According to Roy (1996), multicriteria methods can be divided into three major approaches on the principles of modeling preferences: single-criterion synthesis, outranking, and interactive local judgment.

The single-criterion synthesis approach brings together different points of view within a single synthetic function, which can be further optimized. An example is Multi-Attribute Utility Theory (Keneey \& Raiffa, 1976; Almeida, 2005). In outranking methods the decision maker's 
preferences are modeled using a binary relation of outranking, S, which means "at least as good" (Figueira et al., 2005). This approach can use a number of different methods which include the Electre family (Elimination and Choice Expressing Reality) (Roy \& Bertier, 1973; Vincke, 1992) and the Promethee family (Preference Ranking Organization Method for Enrichment Evaluations) (Belton \& Stewart, 2002). In the interactive local judgment approach, there are methods that use a trial and error approach and a structure for multi-objective mathematical programming (Clímaco et al., 2003).

MCDA is used in several problems and in different contexts, such as: Supplier selection (Alencar \& Almeida, 2008), Preventive maintenance (Almeida, 2005; Cavalcante \& Almeida, 2005; Cavalcante et al., 2010), Project management (Mota \& Almeida, 2007; Alencar \& Almeida, 2010), Information Management (Lopes \& Costa, 2008) and Water resources management (Morais et al., 2010; Trojan \& Morais, 2012).

However, the choice of method will depend on several key factors, such as the time available, the effort required by a given approach, knowledge about the environment, the importance of reaching the most accurate decision, the need to justify the decision to others, the desire to minimize conflicts. In addition, it can highlight other factors, such as problem analysis; the context considered; the information available and its degree of accuracy; the rationality required (compensatory or non compensatory); the decision maker's preference structure; and the problematic of the problem (Almeida \& Costa, 2003; Almeida, 2011).

As to the use of the concept of the ABC classification system, for the problem studied, this sets out to determine the allocation of items under a class-based storage system, regardless of whether new products are included, i.e., the company portfolio may not be static. Moreover, it can to consider more than one criterion for categorizing, such as product profitability, for example. Thus, this is a problematic sorting. For such facts, Electre TRI method is appropriate, because the alternatives are sorted by making a comparison between how they have been evaluated and a stable reference (profile) (Szajubok et al., 2006). This storage location assignment, by the Electre TRI method, besides reaching a class-based allocation as per the decision-maker's preferences, can serve as a category for stock management policies.

\subsection{The Electre TRI method}

The Electre methods evolved over a number of versions: I, II, III, IV, IS and TRI (Alencar et al., 2010). According to Mota \& Almeida (2007) the Electre I and II methods involve only true criteria and are intended for problems involving selection and ranking of alternatives, respectively (see Roy, 1968 and Roy \& Bertier, 1973). For problems that are modeled using pseudo criteria, the Electre III, IV, IS and TRI methods were built. The Electre IS method was developed for the selection of alternatives (see Roy \& Skalka, 1984). The Electre III and IV methods are intended to rank the alternatives from best to worst, and Electre IV problems that cannot introduce any weighting of the criteria (see Roy, 1978 and Hugonnard \& Roy, 1982). Electre TRI is a sorting multicriteria method, i.e., this method allocates the alternatives to predetermined categories. 
The alternative allocation in a class is the result of comparing this alternative and the categories profiles (see Yu, 1992).

According to Figueira et al. (2005) a set of categories must be defined a priori in the sorting problematic. The definition of a category is based on the fact that all potential actions which are assigned to it will be considered further in the same way. In sorting problematic, each action is considered independently from the others in order to determine the categories to which it seems justified to assign it, by means of comparisons to profiles (bounds, limits), norms or references. The sorting problematic refers to absolute judgments. It consists of assigning each action to one of the pre-defined categories which are defined by norms or typical elements of the categories. The assignment of an action ' $a$ ' to a specific category does not influence the category, to which another action ' $b$ ' should be assigned.

An Electre TRI model $\left(\mathrm{M}_{\pi}\right)$ builds a fuzzy outranking relation and then exploits it for decision aid. Decision Makers (DMs) have to set the performance of each action on each criterion; the thresholds that characterize pseudo-criteria; and the importance and veto power of each criterion plus a cut threshold that is used to transform the resulting fuzzy relation into a crisp one, all of which constitute the model's parameters. Parameters are defined in a broad sense, and include input usually referred to as "data", input concerning the DMs' values and beliefs, etc. (Dias \& Clímaco, 2000; Lourenço \& Costa, 2004):

Therefore, the Electre TRI method is designed to assign a set of actions, objects or items to categories. The categories are ordered; let us assume from the worst $\left(C_{1}\right)$ to the best $\left(C_{k}\right)$. Each category must be characterized by a lower and an upper profile. Let $C=\left\{C 1, \ldots, C_{h}, \ldots, C_{k}\right\}$ denote the set of categories (Figueira et al., 2005; Szajubok et al., 2006), as shown in Figure 1.

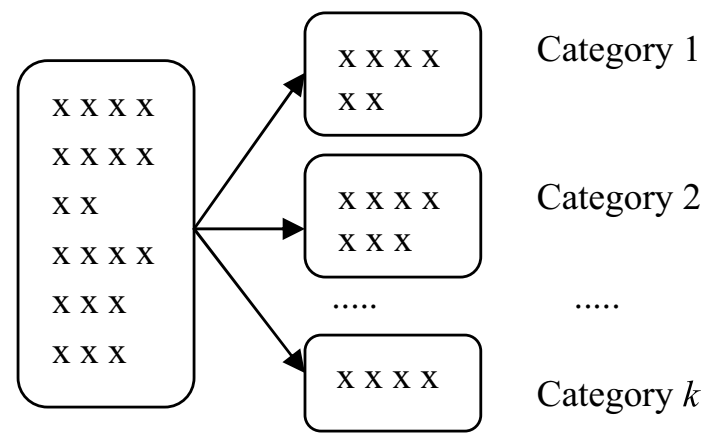

Figure 1 - Sorting problematic - categories ordered. Adapted from Mousseau \& Slowinski (1998).

Two conditions must be checked to validate the claim of the affirmation $a S b_{h}$ (alternative $a$ outranks profile $b_{h}$ ) (Almeida, 2011):

1. Concordance: for an outranking $a S b_{h}$ to be accepted, most criteria need to be in favor on this affirmation; 
2. Non discordance: when the concordance condition is met, none of the criteria must object strongly to the affirmation $a S b_{h}$.

The assignment of a given alternative ' $a$ ' to a certain category $C_{h}$ results from the comparison between the alternative ' $a$ ' and the profiles defining the lower and upper limits of the categories; $b_{h}$ being the upper limit of category $C_{h}$ and the lower limit of category $C_{h+1}$, for all $h=1, \ldots, k$ (see Fig. 2). For a given category limit, $b_{h}$, this comparison relies on the credibility degree $\left(\sigma\left(a, b_{h}\right)\right)$ of the assertions $a S b_{h}$ and $b_{h} S a$ (Figueira et al., 2005).

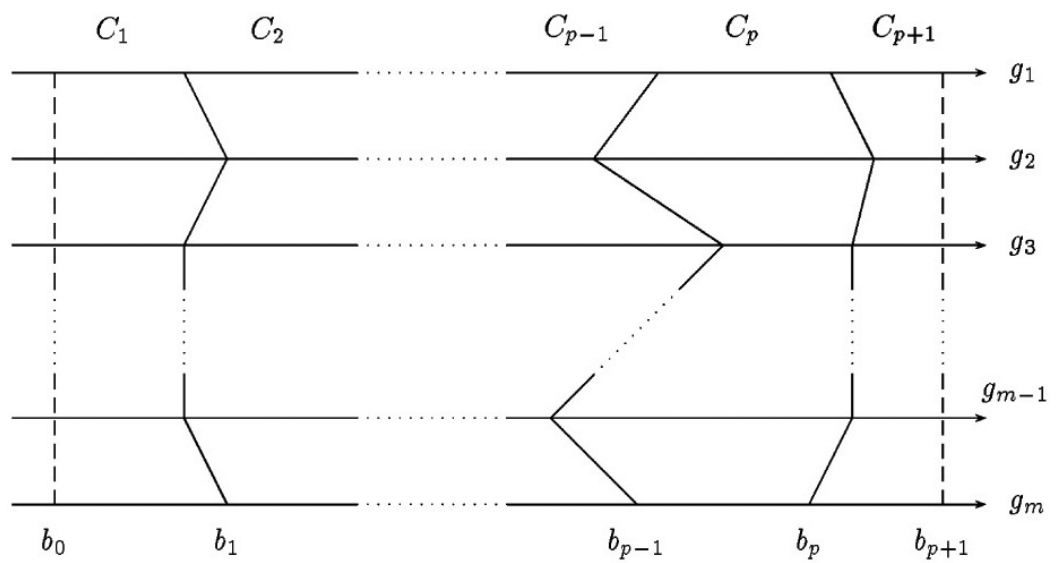

Figure 2 - Definition of categories using limit profiles. Adapted from Mousseau et al. (2000).

In what follows, it will be assumed, without any loss of generality that preferences increase with the value on each criterion. Let's consider: the profiles defined by their evaluations $g_{j}\left(b_{h}\right), \forall j \in$ $F, \forall h \in B$ the weight importance coefficients $k_{j}, \forall j \in F$; the indifference $q_{j}\left(b_{h}\right)$, preference $p_{j}\left(b_{h}\right)$ and veto thresholds $v_{j}\left(b_{h}\right), \forall j \in F, \forall h \in B$. Therefore, according to Mousseau \& Slowinski (1998), determining $\sigma\left(a, b_{h}\right)$ consists of the following steps (the value of $\sigma\left(b_{h}, a\right)$ is computed analogously):

1. Compute the partial concordance index $c_{j}\left(a, b_{h}\right), \forall j \in F$ :

$$
c_{j}\left(a, b_{h}\right)=\left\{\begin{array}{l}
0 \rightarrow \text { if } g_{j}\left(b_{h}\right)-g_{j}(a) \geq p_{j}\left(b_{h}\right) \\
1 \rightarrow \text { if } g_{j}\left(b_{h}\right)-g_{j}(a) \leq q_{j}\left(b_{h}\right) \\
\frac{p_{j}\left(b_{h}\right)+g_{j}(a)-g_{j}\left(b_{h}\right)}{p_{j}\left(b_{h}\right)-q_{j}\left(b_{h}\right)} \text { if not }
\end{array}\right.
$$

2. Compute the global concordance index $c_{j}\left(a, b_{h}\right)$ :

$$
c\left(a, b_{h}\right)=\frac{\sum_{j \in F} k_{j} c_{j}\left(a, b_{h}\right)}{\sum_{j \in F} k_{j}}
$$


3. Compute the discordance index $d_{j}\left(a, b_{h}\right)$,

$$
c_{j}\left(a, b_{h}\right)=\left\{\begin{array}{l}
0 \rightarrow \text { if } g_{j}\left(b_{h}\right)-g_{j}(a) \leq p_{j}\left(b_{h}\right) \\
1 \rightarrow \text { if } g_{j}\left(b_{h}\right)-g_{j}(a)>v_{j}\left(b_{h}\right) \\
\frac{g_{j}\left(b_{h}\right)+g_{j}(a)-p_{j}\left(b_{h}\right)}{v_{j}\left(b_{h}\right)-p_{j}\left(b_{h}\right)} \text { if not }
\end{array}\right.
$$

4. Compute the credibility degree $\sigma\left(a, b_{h}\right)$ of the outranking relation:

$$
\sigma\left(a, b_{h}\right)=c\left(a, b_{h}\right) \cdot \prod_{j \in F} \frac{1-d_{j}\left(a, b_{h}\right)}{1-c\left(a, b_{h}\right)}
$$

where, $\bar{F}=\left\{j \in F: d_{j}\left(a, b_{h}\right)>c\left(a, b_{h}\right)\right\}$.

This level can be defined as the smallest value of the degree of creditability compatible with the assertion $a S b_{h}$ (Figueira et al., 2005). After determining the credibility degree $(\sigma)$, a cutting level $(\lambda)$ should be introduced from the fuzzy relation (Fig. 2) in order to obtain a crisp outranking relation. The values of $\sigma\left(a, b_{h}\right), \sigma\left(b_{h}, a\right)$ and $\lambda$ determine the preference situation between $a$ and $b_{h}$, as follows:

a) $\sigma\left(a, b_{h}\right) \geq \lambda$ and $\sigma\left(b_{h}, a\right) \geq \lambda \rightarrow a S b_{h}$ and $b_{h} S a \rightarrow a I b_{h}$, i.e., $a$ is indifferent to $b_{h}$;

b) $\sigma\left(a, b_{h}\right) \geq \lambda$ and $\sigma\left(b_{h}, a\right)<\lambda \rightarrow a S b_{h}$ and not $b_{h} S a \rightarrow a \succ b_{h}$, i.e., $a$ is preferred to $b_{h}$ (weakly or strongly);

c) $\sigma\left(a, b_{h}\right)<\lambda$ and $\sigma\left(b_{h}, a\right) \geq \lambda$ not $a S b_{h}$ and $b_{h} S a \rightarrow b_{h} \succ a$, i.e., $b_{h}$ is preferred to a (weakly or strongly);

d) $\sigma\left(a, b_{h}\right)<\lambda$ and $\sigma\left(b_{h}, a\right)<\lambda \rightarrow$ not $a S b_{h}$ and not $b_{h} S a \rightarrow a R b_{h}$, i.e., a is noncomparable to $b_{h}$.

Figueira et al. (2005) reported that the objective of the exploitation procedure is to exploit the above binary relations. The role of this exploitation is to propose an assignment. This assignment can be grounded on two well-known pieces of logic.

1. The conjunctive logic in which an action can be assigned to a category when its evaluation on each criterion is at least as good as the lower limit which has been defined for the criterion to be in this category. The action is hence assigned to the highest category fulfilling this condition.

2. The disjunctive logic in which an action can be assigned to a category, if it has, on at least one criterion, an evaluation at least as good as the lower limit which has been defined for the criterion to be in this category. The action is hence assigned to the highest category fulfilling this condition. 
With this disjunctive rule, the assignment of an action is generally higher than with the conjunctive rule. This is why the conjunctive rule is usually interpreted as pessimistic while the disjunctive rule is interpreted as optimistic. This interpretation (optimistic-pessimistic) can be permuted according to the semantic attached to the outranking relation. When no incomparability occurs when comparing an action $a$ to the limits of categories, $a$ is assigned to the same category by both the optimistic and the pessimistic procedures. When $a$ is assigned to different categories by the optimistic and pessimistic rules, $a$ is incomparable to all "intermediate" limits within the highest and lowest assignment categories. The two procedures can be stated as follows:

1. Pessimistic rule. An action $a$ will be assigned to the highest category $C_{h}$ such that $a S b_{h-1}$.

a) Compare $a$ successively with $b_{r}, r=k-1, k-2, \ldots, 0$.

b) The limit $b_{h}$ is the first encountered profile such that $a S b_{h}$. Assign $a$ to category $C_{h+1}$.

2. Optimistic rule. An action $a$ will be assigned to the lowest category $C_{h}$ such that $b_{h} \succ a$.

a) Compare $a$ successively with $b_{r}, r=1,2, \ldots, k-1$.

b) The limit $b_{h}$ is the first encountered profile such that $b_{h} \succ a$. Assign $a$ to category $C_{h}$.

Some authors state that the pessimistic procedure is indicated for situations in which caution is required or where there is scarcity of resources; while the optimistic procedure is indicated for cases where it wants to encourage actions that have particularly attractive or exceptional qualities (Lima et al., 2007).

On the other hand, one of the main difficulties that an analyst must face when interacting with a decision-maker (DM) in order to build a decision aid procedure is how best to elicit from the DM, the various parameters that the DM used in his/her preference model, such as profiles, weights and thresholds. Even if these parameters can be interpreted, it is difficult to fix directly their values and to have a clear global understanding of the implications of these values in terms of the output of the model. Mousseau et al. (2000) presented a general scheme so that the DM could infer these parameters (Fig. 3).

If the steps (Fig. 3) are followed, it is possible to infer the parameters necessary to apply the Electre TRI method. For more information about this inference of the parameters see Mousseau et al. (2000).

\section{STORAGE LOCATION ASSIGNMENT MODEL BY ELECTRE TRI}

The proposal can be summarized by Figure 4. The storage location assignment model by Electre TRI can be divided into three principal steps, such as: (1) structure the problem, (2) generate solutions and (3) determine the final result. 


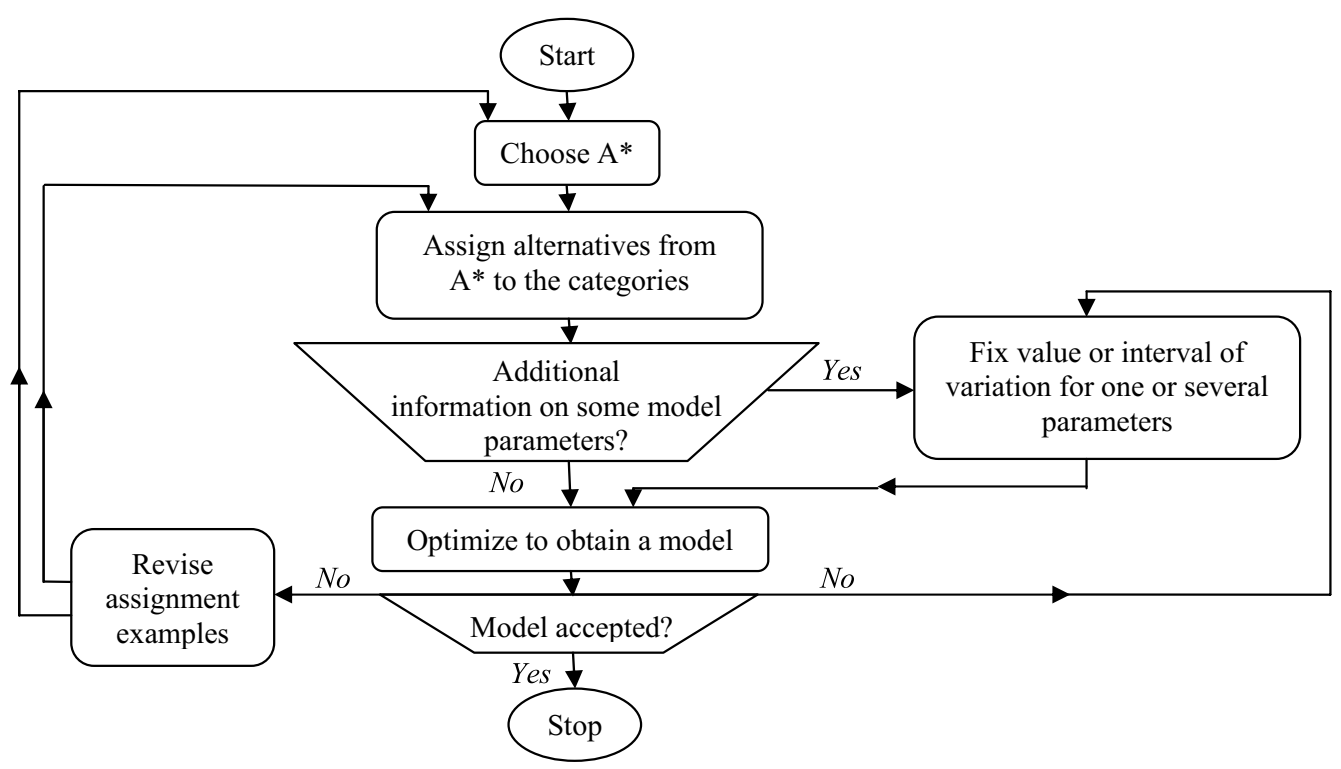

Figure 3 - General scheme of the use of ELECTRE TRI Assistant. Adapted from Mousseau et al. (2000).

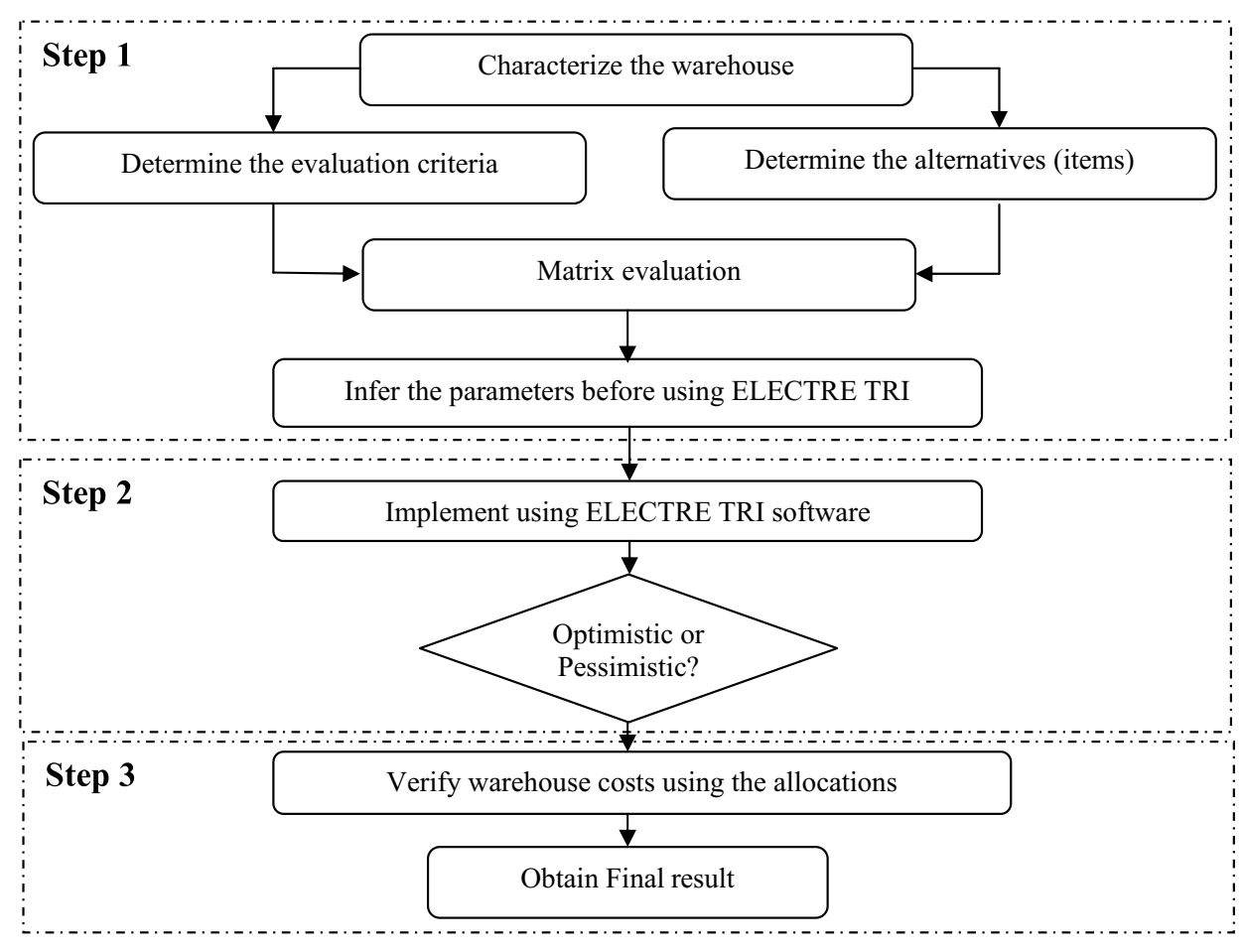

Figure 4 - General model. 
There follows an example to illustrate this proposed model. It is assumed that the DM fully understands the procedure adopted, and is able to evaluate all necessary parameters.

\subsection{Structuring the problem}

In this example, it is considered that the DM wishes to subdivide (or zone the warehouse) the space available for storage into three areas (A, B and C). Thus, the warehouse simulated is rectangular, as in Figure 5. The products or items are allocated randomly into the class-based storage spaces. Note: the number of class-based storage spaces is determined by the DM.

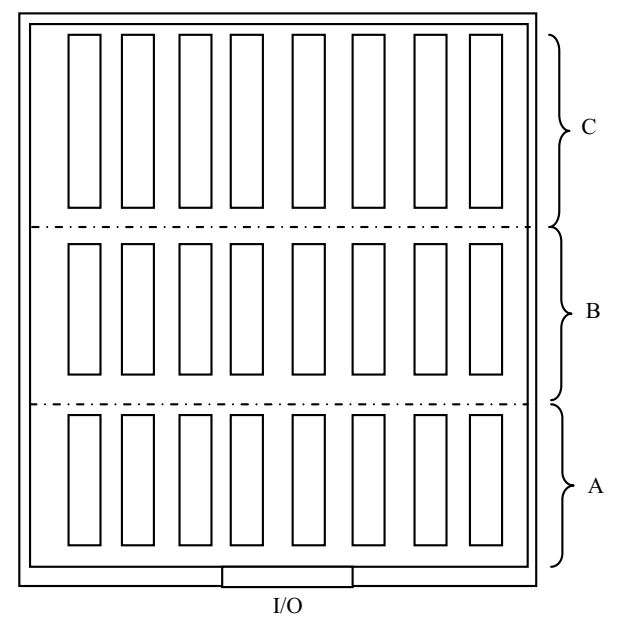

Figure 5 - Illustration of the layout of the storage area in the warehouse.

For this problem the evaluation criteria considered are independent, since the DM's preference for a criterion does not change with changes in the values of other criteria. The criteria selected to determine the best alternative to form classes and locations in the warehouse are:

- Demand: the average frequency of orders by clients for each product. The values are between 0 and 1000 units.

- Size: related to the density of the products which is in the range of between 0 and $1 \mathrm{~m}^{2} / \mathrm{unit}$.

- Profitability: the financial return on each unit of product as a percentage (\%). The values are between 0 and $100 \%$.

- Consumer's sensitivity: a client's particular product may be sensitive to the level of service, for example, the slow delivery of his order. In this criterion the products are evaluated by means of linguistic variables, which are: much, medium, regular, little, very little. To enable this alternative to be used in the model, the assessments made as linguistic variables are cardinalized as follows: (4) much, (3) medium, (2) regular, (1) little (0) very little. 
Since the DM wants to increase operational efficiency in those products which have the highest and consumer sensitivity, and also to reduce the distances traveled for order picking; the products with lowest size, high demand, highest profitability and most sensitivity to the level of customer service are allocated, preferentially, to the area around I/O (input/output).

In this simulated warehouse there are fifty distinct products (alternatives). Table 1 presents the matrix evaluation criteria versus alternatives.

Table 1 - Matrix evaluation: criteria versus alternatives.

\begin{tabular}{|c|c|c|c|c|c|c|c|c|c|}
\hline Items & $\begin{array}{c}\text { Demand } \\
\text { (units) }\end{array}$ & $\begin{array}{c}\text { Size } \\
\left(\mathrm{m}^{2} / \text { unit) }\right.\end{array}$ & $\begin{array}{c}\text { Profit } \\
(\%)\end{array}$ & Sensitivity & Items & $\begin{array}{c}\text { Demand } \\
\text { (units) }\end{array}$ & $\begin{array}{c}\text { Size } \\
\left(\mathrm{m}^{2} / \text { unit }\right)\end{array}$ & $\begin{array}{c}\text { Profit } \\
(\%)\end{array}$ & Sensitivity \\
\hline$a 1$ & 50 & 0.060 & 70 & 4 & $a 26$ & 670 & 0.051 & 100 & 2 \\
$a 2$ & 675 & 0.006 & 33 & 1 & $a 27$ & 255 & 0.149 & 41 & 1 \\
$a 3$ & 260 & 0.019 & 19 & 3 & $a 28$ & 730 & 0.055 & 30 & 3 \\
$a 4$ & 350 & 0.014 & 100 & 4 & $a 29$ & 590 & 0.076 & 65 & 4 \\
$a 5$ & 120 & 0.054 & 10 & 3 & $a 30$ & 60 & 0.767 & 15 & 4 \\
$a 6$ & 560 & 0.014 & 55 & 0 & $a 31$ & 420 & 0.117 & 85 & 2 \\
$a 7$ & 950 & 0.008 & 68 & 4 & $a 32$ & 315 & 0.162 & 25 & 2 \\
$a 8$ & 800 & 0.011 & 20 & 0 & $a 33$ & 280 & 0.189 & 86 & 1 \\
$a 9$ & 450 & 0.026 & 90 & 3 & $a 34$ & 550 & 0.098 & 15 & 3 \\
$a 10$ & 540 & 0.024 & 25 & 1 & $a 35$ & 350 & 0.160 & 92 & 0 \\
$a 11$ & 100 & 0.135 & 5 & 2 & $a 36$ & 840 & 0.071 & 34 & 1 \\
$a 12$ & 230 & 0.061 & 80 & 1 & $a 37$ & 710 & 0.086 & 4 & 1 \\
$a 13$ & 55 & 0.282 & 75 & 2 & $a 38$ & 290 & 0.214 & 100 & 4 \\
$a 14$ & 900 & 0.019 & 30 & 0 & $a 39$ & 380 & 0.171 & 65 & 3 \\
$a 15$ & 35 & 0.514 & 76 & 1 & $a 40$ & 130 & 0.500 & 50 & 2 \\
$a 16$ & 680 & 0.029 & 15 & 4 & $a 41$ & 370 & 0.181 & 10 & 4 \\
$a 17$ & 190 & 0.111 & 53 & 2 & $a 42$ & 915 & 0.077 & 5 & 0 \\
$a 18$ & 790 & 0.028 & 76 & 3 & $a 43$ & 90 & 0.822 & 26 & 2 \\
$a 19$ & 80 & 0.288 & 63 & 3 & $a 44$ & 650 & 0.123 & 45 & 3 \\
$a 20$ & 700 & 0.033 & 54 & 4 & $a 45$ & 230 & 0.357 & 53 & 2 \\
$a 21$ & 855 & 0.029 & 20 & 2 & $a 46$ & 730 & 0.116 & 60 & 4 \\
$a 22$ & 980 & 0.027 & 2 & 4 & $a 47$ & 810 & 0.105 & 21 & 4 \\
$a 23$ & 420 & 0.069 & 47 & 0 & $a 48$ & 970 & 0.093 & 46 & 2 \\
$a 24$ & 130 & 0.231 & 30 & 3 & $a 49$ & 95 & 0.979 & 92 & 1 \\
$a 25$ & 60 & 0.525 & 95 & 0 & $a 50$ & 145 & 0.620 & 32 & 1 \\
\hline
\end{tabular}

The values in Table 1 are relative to the average of the period analyzed. In order to apply Electre TRI, these values, in all criteria, need to be normalized on a scale between 0 and 100 , where 0 means the worst alternative for that criterion and 100 the best alternative on the same criterion.

Moreover, it is emphasized that in Electre TRI, inserting a new alternative will not change the evaluation of others, since they are within the ranges defined for each criterion. This point is appropriate considering that most warehouses do not have a static portfolio of products and, in some cases; it may oscillate with high frequency. 
In this example, for all criteria, the DM established the following parameters: indifference threshold $q=1$, preference threshold $p=2$ and cutting level $\lambda=0.76$. The inferred profiles and criteria weights can be seen in Table 2. Like the alternatives, the values of the profiles should be scaled between 0 and 100 .

Table 2 - Profiles and weights.

\begin{tabular}{|c|c|c|c|c|}
\hline Parameters & Demand & Size & Profit & Sensitivity \\
\hline$b_{1}$ & 60 & 80 & 50 & 50 \\
$b_{2}$ & 40 & 60 & 30 & 25 \\
$k$ & 2 & 1 & 1 & 4 \\
\hline
\end{tabular}

The profiles $b_{1}$ and $b_{2}$ are the limits between classes $\mathrm{A}$ and $\mathrm{B}\left(b_{1}\right)$ and $\mathrm{B}$ and $\mathrm{C}\left(b_{2}\right)$. In this procedure, each alternative was compared to the profiles of the classes.

\subsection{Generating solutions}

The final result, by the optimistic and pessimistic version of Electre TRI method, can be seen in Figure 6. This was calculated with the help of Electre TRI 2.0a software.

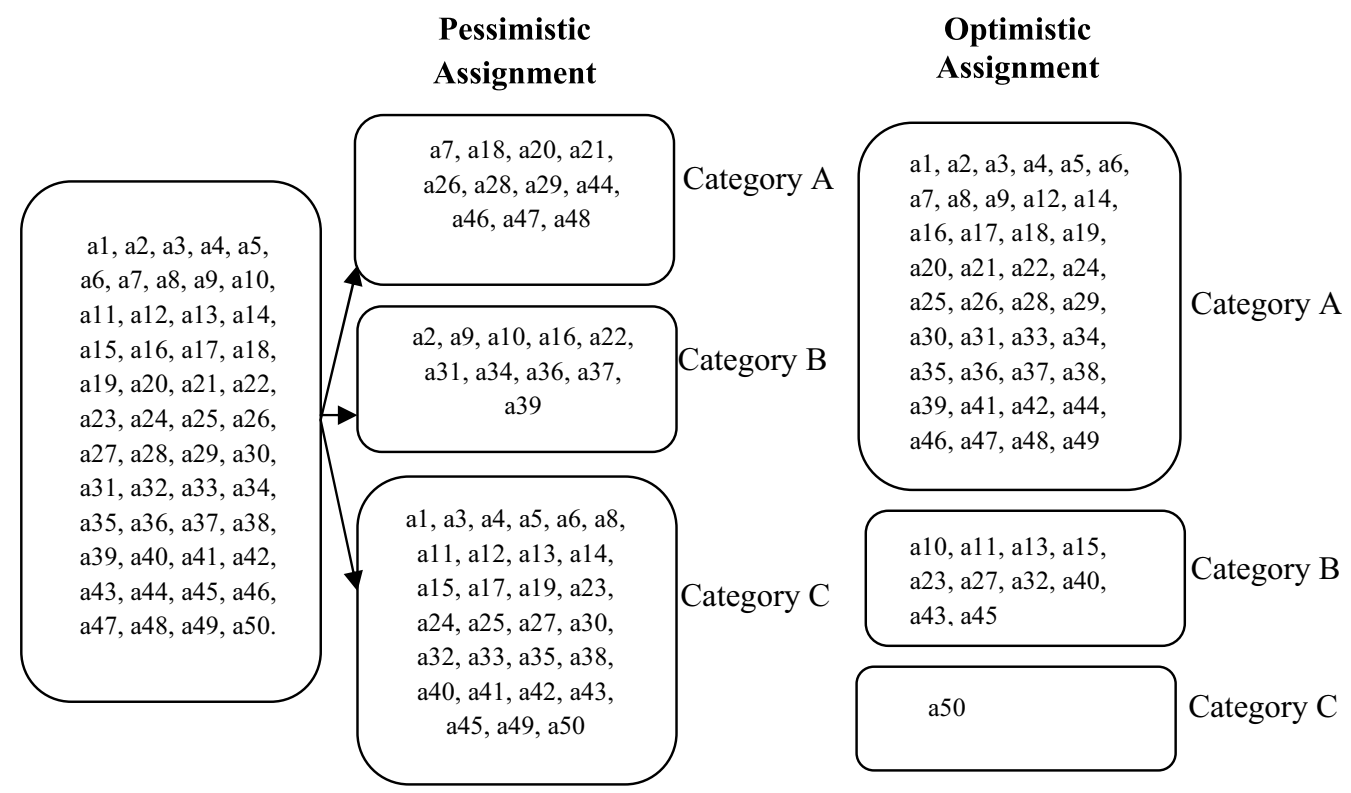

Figure 6 - Illustration of the sorting by Electre TRI.

In the illustrative example, the products are very divergent in their assessment of each criterion, with very good alternatives in some criteria and very bad ones in others. By applying the method, the optimistic version located most of the alternatives in category A, while the pessimistic version those of category C. However, it appears that the pessimistic version is more appropriate, since 
the scenario calls for prudence, i.e., it does not makes sense to allocate to the first category an alternative which is makes the comparison between criteria difficult because this class receives the most attention from stock management policies.

However, this final result can be better for analyzing for decision making purposes which storage location assignment to adopt.

\subsection{The final result}

An important analysis to make, in final decision making about which classification to adopt (optimistic and pessimistic view in ELECTRE TRI), is to analyze the costs involved. However, just the space and order picking costs can be analyzed here, because the opportunity cost for lost sales is difficult to measure in this simulation.

Thus, the products can be randomly located under a class-based system. For simplicity, assume that the total space required for a product is divided by 10 , since they can be stacked, on average, $z=10$ times. Also, assume the warehouse has 5 columns $(x)$, i.e., in each row $(y)$, an allocation of up to $5 \mathrm{~m}^{2}$ of product, on average, is allowed, as shown in Figure 7.

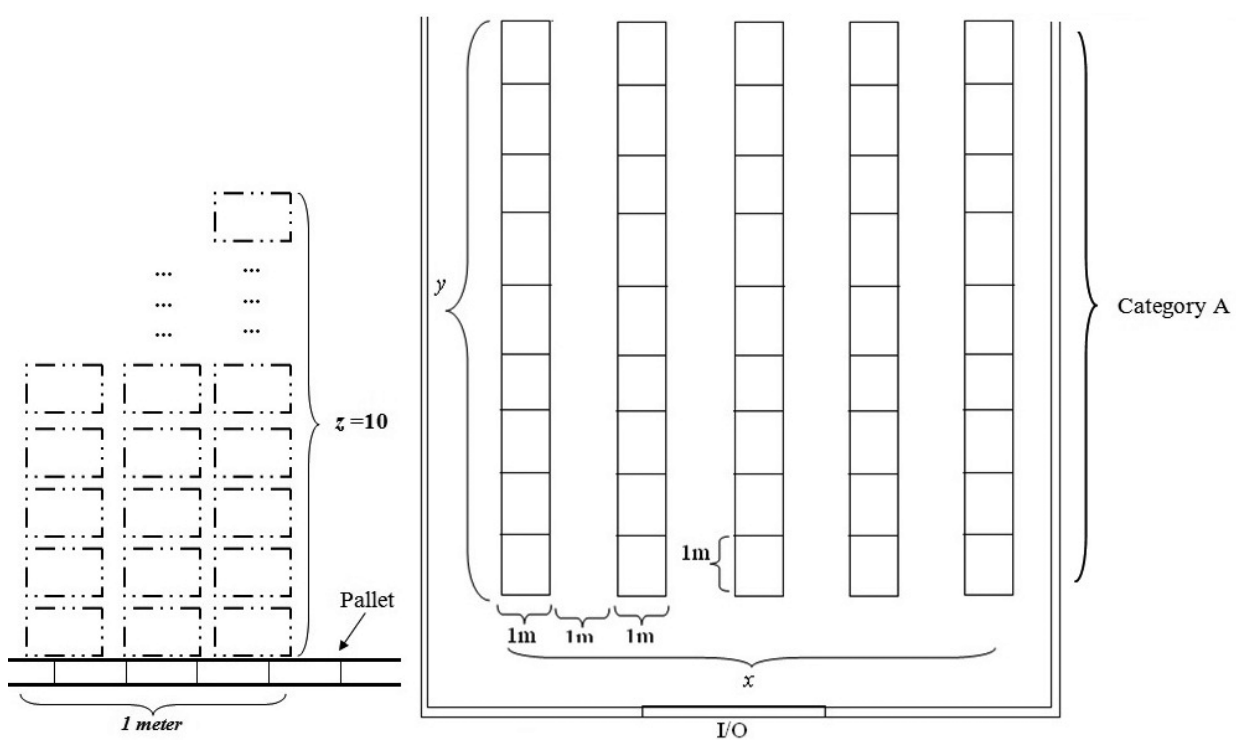

Figure 7 - Illustration of the warehouse layout. Source: Adapted from Fontana \& Cavalcante (2010).

Thus, the average distance traveled to pick up a product within a class is the number of rows $(y)$ in the class divided by 2 (based on the methodology by Muppani \& Adil, 2008a), as shown in Table 3. It is assumed here that only one product is picked up per trip.

The pessimistic rule presented an average distance traveled $4.9 \%$ less than in the optimistic rule, with the same space requirement in the warehouse. Thus, the pessimistic rule requires least effort in order picking and, consequently, has the lowest operational cost. Since storage is a frequent 
Table 3 - Distance traveled to pick up a product.

\begin{tabular}{|c|c|c|c|c|c|c|}
\hline \multicolumn{7}{|c|}{ Optimistic } \\
\hline Class & $\begin{array}{l}\text { Space* } \\
\left(a-m^{2}\right)\end{array}$ & $\begin{array}{c}\text { Demand } \\
(b-\text { units })\end{array}$ & $\begin{array}{c}\text { Rows } \\
(a / 5=c)\end{array}$ & $\begin{array}{l}\text { Rows total } \\
\text { (units) }\end{array}$ & $\begin{array}{c}\text { Average distance } \\
(d-\text { meters })\end{array}$ & $\begin{array}{c}\text { Total distance } \\
(b * d=e-\text { meters })\end{array}$ \\
\hline A & 150.8 & 20220 & 30.16 & 31 & $31 / 2=15.5$ & $313,410.00$ \\
\hline B & 39.9 & 2170 & 7.98 & 8 & $31+8 / 2=35.0$ & $75,950.00$ \\
\hline $\mathrm{C}$ & 8.99 & 145 & 1.80 & 2 & $31+8+2 / 2=40.0$ & $5,800.00$ \\
\hline & Total & & 40.08 & 41 & & $395,160.00$ \\
\hline \multicolumn{7}{|c|}{ Pessimistic } \\
\hline Class & $\begin{array}{c}\text { Space* } \\
\left(a-m^{2}\right)\end{array}$ & $\begin{array}{c}\text { Demand } \\
(b-\text { units })\end{array}$ & $\begin{array}{c}\text { Rows } \\
(a / 5=c)\end{array}$ & $\begin{array}{c}\text { Rows total } \\
\text { (units) }\end{array}$ & $\begin{array}{c}\text { Average distance } \\
(d-\text { meters })\end{array}$ & $\begin{array}{c}\text { Total distance } \\
(b * d=e-\text { meters })\end{array}$ \\
\hline 1 & 53.75 & 8445 & 10.75 & 11 & $11 / 2=5.5$ & $46,447.50$ \\
\hline 2 & 36.35 & 6225 & 7.27 & 8 & $11+8 / 2=15.0$ & $93,375.00$ \\
\hline \multirow[t]{2}{*}{3} & 109.59 & 7865 & 21.92 & 22 & $11+8+22 / 2=30.0$ & $235,950.00$ \\
\hline & Total & & 40.08 & 41 & & $375,772.50$ \\
\hline
\end{tabular}

*The space is estimated by the ratio between demand and size.

activity, which does not adds value to the product, any improvement in its performance can result in the company making a surplus. Moreover, the allocation made by the pessimistic rule enabled a substantially lower number of products to be allocated to the first class (A), which allows the best form of stock, such as the ABC curve technique.

Furthermore, Bouyssou \& Marchant (2005) axiomatically proved that the two versions of Electre TRI are rather different: only the pessimistic version fits into the framework of noncompensatory sorting models. According to them, this is related to the fact that most studies attempt to infer the parameters of an Electre TRI model from assignment examples (i.e. from a division defined on a subset of ' $\mathrm{X}$ '), using mathematical programming techniques and have only considered the pessimistic version of the method. Indeed, the models presented by Bouyssou \& Marchant, in 2005, seem to show that the optimistic version of Electre TRI is at variance with the general principles underlying most of the Electre techniques. Therefore, in addition to the above observations, this statement proves that the pessimistic rule is more appropriate.

\section{DISCUSSIONS AND LIMITATIONS}

The Electre TRI method proved to be appropriate due its characteristic of non-compensation between the criteria. Since all the characteristics or criteria raised are important in making an evaluation of the efficiency of the warehouse and the storage location assignment system, an alternative with a bad evaluation on a criterion should not be compensated by a good evaluation on another criterion. Moreover, when a new product is stocked in the warehouse, there is no need to reclassify the storage location assignment of the others because Electre TRI compares the alternative and the class profiles. In this case, all that is necessary is to review whether there is space available in the class for this new product. If there is not, reorganization is needed. 
Moreover, it is believed that if customers are time-sensitive, the service adopted should measure which service provides the shortest response time possible to raise the service level offered by the company. This is possible because of the specific measures adopted for each category of consumer products. The category of products, resulting from ELECTRE TRI, besides finding the best location in the warehouse to optimize these physical operations, is also able to consider the sensitivity of the group of customers who require each product. To extend, this research, it is suggested that the individual client's sensitivity be considered rather than that of the client group. Because, in some cases, the influence of an individual client may be stronger than the influence of a customer group and deserve special attention.

However, the importance should be emphasized of examining carefully the categories generated, and especially the parameters inferred so that the DM's preferences are really represented, to ensure that very relevant alternatives are not under-rated and other less relevant alternatives are not overrated.

The allocation made by the pessimistic view provides a decrease in the travel distance in order picking by almost five percent, when compared to the optimistic version. This is a significant percentage when it comes to a warehouse with a high turnover of products. Moreover, as the time spent on storage is an essential factor in the total time spent in the activity order cycle, and the distance traveled is one of the crucial factors in determining this time, it becomes important to study viable and sustainable means that will minimize distances in order picking.

In addition, using dedicated storage and randomized storage makes it difficult to apply specific stock management policies to each product, and the latter also considerably increases the costs and complexities of order picking. It should be noted that the proposed idea is not intended to categorize lower operational cost, but one that can optimize the location assignment of the items stocked, at the same time as streamlining the process of stock management.

To sum up, Electre TRI appears to be an attractive method to improve the warehouse operation. It is known that, in most multicriteria methods, understanding the decision maker's preferences and the inference of the parameters are the most difficult part of applying them. For this reason, several studies were undertaken to assist in this task, such as by Mousseau et al. (2000). However, this paper does not aim to further this issue. The proposal of the Electre TRI method used for storage location assignment into categories is feasible and it is easier than allocating products without the support of a specific method.

\section{CONCLUDING REMARKS}

This study began with the goal of using a multicriteria sorting method to evaluate the characteristics of products in a warehouse. By doing so, it was possible to assign storage location to items in a specific area for each form of class-based storage and, also, to adopt strategies of stock management appropriate to each class. Therefore, the outranking method, Electre TRI, was chosen due to its characteristic of non-compensation between the criteria and because the method allows the insertion and/or removal of alternatives without this changing the allocation of others. 
The Electre TRI method provides two versions for the sorting problematic, called the optimistic assignment and the pessimistic assignment. In the illustrative example, the pessimistic rule was more efficient both in terms of minimizing the average travel distance in order picking, as well as in terms of gains from adopting specific policies in stock management. Moreover, the paper by Bouyssou \& Marchant (2005) proves, axiomatically, that the optimistic rule endows the results with some features, which makes its use non appropriate in the scenario analyzed, as discussed above.

To sum up, the Electre TRI method is pertinent, in sorting products in a warehouse, because it considers both the objective criteria on products (e.g., size of items) and the subjective criteria on clients (e.g., the sensitivity of the customer service level). Moreover, this method makes decisions on storage to be taken more easily than do those of other methods found in the literature.

\section{ACKNOWLEDGMENTS}

This paper is part of research studies funded by Coordenação de Aperfeiçoamento de Pessoal de Nivel Superior (CAPES) and Conselho Nacional de Desenvolvimento Cientifico e Tecnológico (CNPq).

\section{REFERENCES}

[1] Alencar LH \& Almeida AT. 2008. Multicriteria decision group model for the selection of suppliers. Pesquisa Operacional, 28(2): 321-337.

[2] Alencar LH, Almeida AT \& Morais DC. 2010. A Multicriteria group decision model aggregating the preferences of decision-makers based on Electre methods. Pesquisa Operacional, 30: $687-702$.

[3] Alencar LH \& Almeida AT. 2010. A Model for Selecting Project Team Members using Multicriteria Group Decision Making. Pesquisa Operacional (Impresso), 30: 221-236.

[4] Almeida AT. 2005. Modelagem multicritério para seleção de intervalos de manutenção preventiva baseada na teoria da utilidade multiatributo. Pesquisa Operacional, 25(1): 69-81.

[5] Almeida AT. 2011. O conhecimento e o uso de métodos multicritério de apoio a decisão. Recife: Ed. Universitária da UFPE.

[6] Almeida AT \& COSTA APCS. 2003. Aplicações com Métodos Multicritério de Apoio a Decisão. Recife: Ed. Universitária da UFPE, 14.

[7] Belton V \& StewART J. 2002. Multiple criteria decision analysis - an integrated approach. London: Kluver Academic Publishers.

[8] Bouyssou D \& Marchant T. 2005. An axiomatic approach to Electre Tri. In: Barthélemy J-P \& LENCA P (eds.). 2005. Advances in Multicriteria Decision Aid. ENST Bretagne, (ISBN 29523875-0-8): 9-20.

[9] BRYNZÉR H \& JOHANSSON MI. 1996. Storage location assignment: Using the product structure to reduce order picking times. Int. J. Production Economics, 46: 595-603. 
[10] Cavalcante CaV, Pires Ferreira RJ \& Almeida AT. 2010. A preventive maintenance decision model based on multicriteria method PROMETHEE II integrated with Bayesian approach. IMA Journal of Management Mathematics, 21: 333-348.

[11] CaValcante CAV \& Almeida AT. 2005. Modelo multicritério de apoio a decisão para o planejamento de manutenção preventiva utilizando PROMETHEE II em situações de incerteza. Pesquisa Operacional, 25(2): 279-296.

[12] Chew EP \& TANG LC. 1999. Travel time analysis for general item location assignment in a rectangular warehouse. European Journal of Operational Research, 112: 582-597.

[13] Chen M, Huang C, Chen K \& Wu H. 2005. Aggregation of orders in distribution centers using data mining. Expert Systems with Applications, 28: 453-460.

[14] Chen Y, Li K, Kilgour DM \& Hipel KW. 2008. A case-based distance model for multiple criteria $\mathrm{ABC}$ analysis. Computers \& Operations Research, 35(3): 776-96.

[15] CHEN M \& WU H. 2005. An association-based clustering approach to order batching considering customer demand patterns. Omega - International Journal of Management Science, 33: 333-343.

[16] Chu C-W, Liang G-S \& LiaO C-T. 2008. Controlling inventory by combining ABC analysis and fuzzy classification. Computers \& Industrial Engineering, 55: 841-851.

[17] Clímaco NC, Antunes CH \& Alves MJG. 2003. Programação linear multiobjetivo: do modelo de programação linear clássico à consideração explícita de várias funções objetivo. Universidade de Coimbra.

[18] Dias LC \& CLímaco JN. 2000. ELECTRE TRI for Groups with Imprecise Information on Parameter Values. Group Decision and Negotiation, 9: 355-377.

[19] Daniels RL, Rummel JL \& Schantz R. 1998. Model for warehouse order picking. European Journal of Operational Research, 115: 1-17.

[20] Figueira J, Mousseau V \& Roy B. 2005. Chapter 4. Electre Methods. In: Multiple criteria decision analysis: state of the art surveys. International Series in Operations Research \& Management Science, 78(3): 133-153.

[21] Fontana ME \& CaValcante CAV. 2010. Utilização do número de clientes para formação de classe e localização dos itens para minimização da distância percorrida para picking. XXX Encontro Nacional de Engenharia de Produção - ENEGEP. São Carlos, Brasil.

[22] Freitas FFt, Nascimento KSC, Pelaes TS \& FranÇa VO. 2006. Otimização das operações de Movimentação e Armazenagem de materiais através de rearranjo físico: uma proposta de melhoria para um almoxarifado da esfera pública. XXVI Encontro Nacional de Engenharia de Produção ENEGEP, Fortaleza, Brasil.

[23] Goebel D. 1996. Logística - otimização do transporte e estoques na empresa. Estudos em Comércio Exterior, ECEX/IE/UFRJ, Rio de Janeiro, 1(1).

[24] Gu J, Goetschalckx M \& McGinnis LF. 2007. Research on warehouse operation: A comprehensive review. European Journal of Operational Research, 177: 1-21.

[25] Henn S, Koch S, Doerner KF, Strauss C \& Wëscher G. 2010. Metaheuristics for the order batching problem in manual order picking systems. Business Research, 3(1): 82-105. 
[26] Hsien S \& Tsai K-C. 2001. A BOM Oriented Class-Based Storage Assignment in an Automated Storage/Retrieval System. Int. J. Adv. Manuf. Technol., 17: 683-691.

[27] Hugonnard J \& Roy B. 1982. Le plan d'extension du métro en banlieue parisienne, un cas type d'application de l'analyse multicritère. Les Cahiers Scientifiques de la Revue Transports, 6: 77-108.

[28] JANE C \& LAIH Y. 2005. A clustering algorithm for item assignment in a synchronized zone order picking system. European Journal of Operational Research, 155: 489-496.

[29] Keeney RL \& Raiffa H. 1976. Decision with Multiple Objectives: Preferences and Value Tradeoffs. John Wiley \& Sons.

[30] Koster R, Le-Duc T \& Roodbergen KJ. 2007. Design and control of warehouse order picking: a literature review. European Journal of Operational Research, 182: 481-501.

[31] Le-Duc T \& Koster RBM(M). 2005. Travel distance estimation and storage zone optimization in a 2-block class-based storage strategy warehouse. International Journal of Production Research, 43: 3561-3581.

[32] Li M, CHEN X \& LiU C. 2008. Pareto and niche genetic algorithm for storage location assignment optimization problem. The $3^{\text {rd }}$ International Conference on Innovative Computing Information and Control-IEE.

[33] Lima JefW, Neves Cl, Santos RM, Vergara Fe, Souza MaA \& Cordeiro Neto OM. 2007. Desenvolvimento de aplicativo para uso do método multicritério Electre TRI. I Simpósio de Recursos Hídricos do Norte e Centro-Oeste - Cuiabá.

[34] Lopes YG \& COSTA APCS. 2008. Modelo de decisão para seleção de sistemas de informação baseado decisão multicritério e programação inteira 0-1. Revista Gestão Industrial, 3: 283-298.

[35] LOURENÇO RP \& Costa JP. 2004. Using ELECTRE TRI outranking method to sort MOMILP nondominated solutions. European Journal of Operational Research, 153: 271-289.

[36] Meghelli-Gaouar N \& Sari Z. 2010. Assessment of performance of a class-based storage in a flow-rack AS/RS. Journal of Studies on Manufacturing, 1: 100-107.

[37] Mota CMM \& Almeida AT. 2007. Método multicritério Electre IV-H para priorização de atividades em projetos. Pesquisa Operacional, 27(2): 247-269.

[38] Morais DC, Cavalcante CAV \& Almeida AT. 2010. Priorização de áreas de controle de perdas em redes de distribuição de água. Pesquisa Operacional (Impresso), 30: 15-32.

[39] Mousseau V \& SLOWInski R. 1998. Inferring an ELECTRE TRI Model from Assignment Examples. Journal of Global Optimization, 12: 157-174.

[40] Mousseau V, Slowinski R \& Zielniewicz P. 2000. A user-oriented implementation of the ELECTRE-TRI method integrating preference elicitation support. Computers \& Operations Research, 27: 757-777.

[41] MupPANI VR \& ADIL GK. 2008a. Efficient formation of storage classes for warehouse storage location assignment: A simulated annealing approach. International Journal of Management Science, 36: 609-618.

[42] MupPani VR \& ADIL GK. 2008b. A branch and bound algorithm for class based storage location assignment. European Journal of Operational Research, 189: 492-507. 
[43] Nicolini M \& Zovatto L. 2009. Optimal Location and Control of Pressure Reducing Valves in Water Networks. Journal of Water Resources Planning and Management-Asce, 135(3): 178-187.

[44] Petersen CG \& AASE G. 2004. A comparison of picking, storage, and routing policies in manual order picking. International Journal of Production Economics, 92: 11-19.

[45] Ramanathan R. 2006. ABC inventory classification with multiple-criteria using weighted linear optimization. Computers \& Operations Research, 33: 695-700.

[46] Rouwenhorst B, Reuter B, Stockrahm V, Van Houtum GJ, Mantel RJ \& ZiJm WhM. 2000. Warehouse design and control: Framework and literature review. European Journal of Operational Research, 122: 515-533.

[47] Roy B. 1968. Classement et choix en présence de points de vue multiple: la méthode Electre. R.I.R.O., 8: $57-75$.

[48] Roy B. 1978. Electre III: Um algorithme de classements fondé sur une représentation floue des préférences en présence de critères multiples. Cahier du CERO, 20(1): 3-24.

[49] Roy B. 1996. Multicriteria methodology for decision aiding. Netherlands, Kluwer Academic Publishers.

[50] RoY B \& BERTIER P. 1973. La méthode Electre II - une application au média-planning. Operational Research: 291-302.

[51] Roy B \& SKalKa JM. 1984. ELECTRE IS: Aspects méthodologiques et guide d'utilisation. Document du Lamsade, 30. Université de Paris-Dauphine, Paris.

[52] Syntetos AA, Keyes M \& Babai MZ. 2009. Demand categorisation in a European spare parts logistics network. International Journal of Operations \& Production Management, 29(3): 292-316.

[53] Szajubok NK, Mota CMM \& Almeida AT. 2006. Uso do método multicritério Electre TRI para classificação de estoques na construção civil. Pesquisa Operacional, 26(3): 625-648.

[54] Trojan F \& MORAIS DC. 2012. Using Electre TRI to support maintenance of water distribution networks. Pesquisa Operacional (Impresso), 32: 1-20.

[55] Van Den Berg JP, Sharp GP, Gademann AJRM \& Pochet Y. 1998. Forward-reserve allocation in a warehouse with unit-load replenishments. European Journal of Operational Research, 111: 98-113.

[56] VAn Den Berg JP \& ZiJM WH. 1999. Models for warehouse management: Classification and examples. International Journal of Production Economics, 59: 519-528.

[57] VincKe P. 1992. Multicriteria Decision-Aid. Wiley, Bruxelles.

[58] YU W. 1992. ELECTRE TRI - Aspects methodologiques et guide d'utilisation. Document du Lamsade 74, Université Paris-Dauphine. 